\title{
Antonim Mutlak dalam Bahasa Jawa: Kajian Semantik Leksikal
}

\author{
Absolute Antonyms in Javanese Language: Lexical Semantics Study
}

\author{
Endang Sri Maruti ${ }^{1, *}$ dan Bambang Eko Hari Cahyono ${ }^{2}$ \\ ${ }^{1,2}$ Universitas PGRI Madiun \\ ${ }^{1}$ Corresponding email: endang@unipma.ac.id \\ ${ }^{2}$ Email: behc@unipma.ac.id
}

\begin{abstract}
The purpose of this study is to describe and classify absolute antonyms in Javanese. This research is a descriptive qualitative type. The data are in the form of words, phrases, clauses, and sentences containing absolute antonyms taken from Javanese textbooks and textbooks in elementary and high schools. Data collection techniques with documentation, listening, and record. The data were analyzed using the "agih" method with the substitution technique and the reflexive-introspective method. The results show that the meaning of contrast does not mean the known contrast, which has been taught in schools so far. Based on the meanings explained by experts, the meaning of antonyms is more complex, and the types of antonyms also vary. In absolute antonyms, several properties must be fulfilled, $A$ and $B$ are said to be absolute antonyms if $A$ is negated, the meaning is the same as $B$, and vice versa if $B$ is negated, the meaning is the same as $A$. This pattern can be used as a reference for teachers to teach contrasting meaning material, especially in absolute antonyms.
\end{abstract}

Keywords: absolute antonym, Javanese, lexical semantics

Abstrak: Tujuan penelitian ini untuk mendeskripsikan dan menglasifikasikan antonim mutlak dalam Bahasa Jawa. Penelitian ini berjenis kualitatif deskriptif. Data berupa kata, frasa, klausa, dan kalimat yang mengandung antonim mutlak yang diambil dari buku ajar dan buku teks berbahasa Jawa di sekolah, baik sekolah dasar maupun sekolah menengah. Teknik pengumpulan data dengan dokumentasi, simak, dan catat. Data dianalisis menggunakan metode agih dengan teknik substitusi dan metode refleksif-introspektif. Hasil penelitian menunjukkan bahwa arti kontras bukan berarti kontras yang diketahui dan yang telah diajarkan di sekolahsekolah selama ini. Berdasarkan makna yang dijelaskan oleh para ahli, makna antonim lebih kompleks dan jenis antonim juga beranekaragam. Pada antonim mutlak, ada beberapa sifat yang harus terpenuhi, A dan B dikatakan sebagai antonim mutlak jika A dinegasikan, maknanya sama dengan B, dan sebaliknya jika B dinegasikan maknanya sama dengan A. Pola ini bisa dijadikan rujukan bagi para guru untuk mengajarkan materi makna kontras khususnya pada antonim mutlak.

Kata kunci: antonim mutlak, Bahasa Jawa, semantik leksikal

To cite this article:

Maruti, E. S., \& Cahyono, B. E. H. (2021). Antonim Mutlak dalam Bahasa Jawa: Kajian Semantik Leksikal. Diglosia: Jurnal Kajian Bahasa, Sastra, dan Pengajarannya, 4(4), 387-400. https://doi.org/10.30872/diglosia.v4i4.237 


\section{A. PENDAHULUAN}

Dalam tuturan sebuah bahasa seringkali ditemui adanya hubungan kemaknaan antara sebuah kata atau satuan bahasa yang lain dengan kata atau satuan bahasa lainnya, termasuk bahasa Jawa dalam hal ini. Hubungan inilah yang disebut dengan relasi makna. Secara garis besar, relasi makna dalam semantik dibedakan menjadi dua, yaitu relasi yang kontras dan relasi yang similar. Relasi makna kontras menunjukkan adanya hubungan yang berlawanan atau oposisi, yaitu: biner (oposisi mutlak), taksonomik, dikotomik (oposisi kutub), dan gradual (oposisi bertingkat). Dalam tulisan ini hanya dibahas tentang relasi makna kontras khususnya antonim mutlak dalam Bahasa Jawa dengan pendekatan Semantik leksikal.

Antonim berada pada wilayah leksikal, yakni memiliki bagian tertentu yang memungkinkan suatu wacana terpadu dalam suatu gagasan (Pateda, 2010). Bagian tersebut berfungsi sebagai pengait antarbagian di dalam wacana sehingga wacana yang bersangkutan utuh sebagai satu kesatuan makna. Dalam hal ini, piranti aspek leksikal difungsikan untuk membedah makna kata yang berantonim. Kata antonim berasal dari bahasa Yunani Kuno, yakni dari kata anoma yang berarti nama dan kata anti yang berarti melawan (Pateda, 2010). Berdasarkan hal itu, maka makna harfiahnya adalah nama lain untuk benda yang lain. Dalam Kamus Besar Bahasa Indonesia (KBBI), kata antonim diartikan sebagai kata yang berlawanan makna dengan kata lain, seperti kata pandai merupakan antonim dari kata bodoh. Pada kedua kata tersebut jelas terdapat makna yang bersinggungan satu sama lain yaitu kata pandai melambangkan orang yang cepat menangkap pelajaran/ilmu dan mengerti sesuatu, sedangkan kata bodoh melambangkan orang yang sulit menangkap pelajaran.

Antonim adalah ungkapan (biasanya berupa kata, tetapi dapat juga berupa frasa atau kalimat) yang dianggap bermakna kebalikan dari ungkapan lain (Pateda, 2010). Keraf (1993) berpendapat bahwa oposisi mutlak sebagai oposisi biner, yaitu oposisi yang menganut dua pandangan. Antonimi adalah hubungan semantik antar dua buah satuan ujaran yang maknanya menyatakan kebalikan, pertentangan, atau kontras antara yang satu dengan yang lain (Abdul, 2012). Secara sederhana, antonim dapat dikatakan sebagai kata-kata yang berlawanan makna.

Alasan membahas antonim mutlak secara mendalam karena masih sedikit ahli bahasa yang mendeskripsikannya, itupun masih sangat terbatas kajiannya, sehingga belum jelas konsep yang disampaikan. Antonim mutlak merupakan antonim yang terdiri atas dua bagian yang memisahkan satu sama lain sehingga disebut sebagai oposisi kembar, yaitu oposisi yang merangkul dua pandangan, artinya memiliki pasangan yang utuh, yaitu pasangan yang ada adalah pasangan tetap dan tidak bisa digantikan dengan kata yang lain (Setiawaty et al., 2021). Kontradiksi ini menyatakan bahwa pasangan kata itu merupakan satu-satunya kata untuk menggambarkan perlawanan satu sama lain. Jika kata itu ditegaskan dan konsepnya sejajar mutlak dengan kata yang lainnya, maka pasangan itu disebut antonim biner, seperti pada kata hidup dan mati.

Pasangan antonim mutlak dapat ditentukan dengan menggunakan tes seperti berikut: Jika tidak A sama dengan B, dan sebaliknya jika tidak B sama dengan A (Guessoum et al., 2016). Oleh karena itu, A dan B adalah antonim mutlak. Jika tidak mati ia hidup, jika tidak hidup ia mati. Dalam Bahasa Jawa yang memiliki tingkat tutur yang bermacam-macam (Padmosoekotjo, 1956), penggunaan antonim juga harus memperhatikan tingkat tutur. Pasangan antonim umumnya berada pada 
tataran yang sama. Kata sugeng 'sehat' berantonim mutlak dengan kata seda 'meninggal' yang sama-sama dalam tataran krama. Contoh pasangan dalam tataran ngoko adalah kata urip 'hidup' dan mati 'mati'.

Penelitian tentang antonim telah banyak dilakukan, namun belum ada penelitian tentang antonim dalam Bahasa Jawa. Setiarini (2018) meneliti struktur antonim penerjemahan Bahasa Inggris dan Bahasa Indonesia dalam alkitab. Antonim dalam Bahasa Arab lebih banyak diteliti dalam al-Qur'an berdasarkan kajian semantik (Ridlo, 2017; Irfanuddin \& Halimi, 2019; Kaswati, 2019; Ningrum, 2020; Tumanggor, 2020). Antonim dalam Bahasa daerah lainnya sudah pernah dilakukan. Fauziah et al. (2017) meneliti relasi makna dalam Bahasa Melayu. Antonim dalam Bahasa Madura pernah diteliti oleh Mashudi et al. (2019), dan Sugita \& Mus (2019) meneliti antonim Bahasa Modo. Berdasarkan hasil kajian di atas, belum ada penelitian yang secara khusus membahas tentang antonim mutlak dalam Bahasa Jawa. Oleh sebab itu, penelitian ini berbeda dan penting untuk dilakukan mengingat banyaknya jenis antonim dalam Bahasa Jawa dan beragamnya tingkat tutur dalam Bahasa Jawa yang menimbulkan inkonsisten dalam penggunaannya.

Merujuk pada latar belakang di atas, penelitian ini berfokus pada bentuk antonim mutlak dalam Bahasa Jawa berdasarkan kajian semantik leksikal. Adapun tujuan penelitian ini adalah untuk mendeskripsikan dan menglasifikasikan bentuk antonim mutlak dalam Bahasa Jawa.

\section{B. METODE}

Penelitian ini berpendekatan kualitatif deskriptif. Data berupa kata, frasa, klausa, dan kalimat yang mengandung antonim mutlak yang diambil dari buku ajar dan buku teks berbahasa Jawa di sekolah, baik sekolah dasar maupun sekolah menengah. Teknik pengumpulan data dengan dokumentasi, simak, dan catat. Data yang telah terkumpul kemudian dianalisis dengan menggunakan beberapa langkah sesuai teori Miles \& Huberman (1994) yaitu menganalisis data dengan tiga langkah: kondensasi data (data condensation), menyajikan data (data display), dan menarik simpulan atau verifikasi (conclusion drawing and verification). Adapun metode analisis datanya adalah metode agih dengan teknik substitusi (Sudaryanto, 1993) dan metode refleksif-introspektif. Teknik substitusi dalam metode agih biasa disebut dengan teknik ganti. Teknik dasar metode agih disebut teknik Bagi Unsur Langsung atau teknik BUL. Disebut demikian karena cara yang digunakan pada awal kerja analisis adalah membagi satuan lingual data menjadi beberapa bagian atau unsur dan unsurunsur yang bersangkutan dipandang sebagai bagian yang langsung membentuk satuan lingual yang dimaksud.

\section{PEMBAHASAN}

Antonim mutlak dalam Bahasa Jawa dapat diklasifikasikan berdasarkan jenis kata. Adapun antonim mutlak berdasarkan jenis kata dalam Bahasa Jawa (Sasangka et al., 2001). Dalam penelitian ini hanya tiga jenis kata saja yang digunakan, yaitu antonim mutlak dalam bentuk (1) kata sifat, (2) kata benda, dan (3) kata kerja. Berikut uraian secara lengkapnya.

\section{Antonim Mutlak Kata Sifat}

Antonim mutlak kata sifat merupakan antonim mutlak yang terdiri atas kata sifat. Kata sifat ini dapat menggambarkan sifat manusia, hewan, benda, atau sesuatu 
yang bersifat netral (Sasangka et al., 2001). Netral di sini artinya adalah situasi itu dapat merepresentasikan sifat atau keadaan manusia, binatang, ataupun suatu benda.

Antonim mutlak kata sifat berdasarkan perihal sifat yang digambarkan dapat dibedakan menjadi berikut.

\section{a. Harga}

Harga menunjukkan nilai jual suatu benda. Pasangan antonim mutlak pada harga dalam Bahasa Jawa adalah larang 'mahal' dan murah 'murah'.

larang $><$ murah

Contoh penggunaan antonim mutlak dalam kalimat adalah sebagai berikut.

(1) Tas iku regane larang. 'Tas itu harganya mahal'

(1a) Tas iku regane ora murah. 'Tas itu harganya tidak murah'.

Kata larang 'mahal' dan murah 'murah'termasuk dalam antonim mutlak. Hal itu terbukti dari kata murah jika dinegasikan menjadi ora murah. Frasa ora murah 'tidak murah' artinya sama dengan larang 'mahal'. Dan sebaliknya, jika kata larang 'mahal' dinegasikan dengan menggunakan kata tidak menjadi ora larang 'tidak mahal', dan frasa ora larang itu artinya sama dengan murah. Hal ini sejalan dengan Suhartatik \& Azis (2019) yang menyatakan bahwa relasi antara dua buah kata yang berantonim bersifat dua arah, dan tidak dapat diingkari dengan kata tidak.

\section{b. Keindahan}

Keindahan berasal dari kata indah, yaitu hal yang menunjukkan suatu keadaan yang menimbulkan kenyamanan bagi yang memandang. Keindahan dapat digunakan pada manusia, hewan, tumbuhan, maupun benda-benda lainnya.

$$
\text { apik }><\text { elek }
$$

Kata apik 'bagus' dan elek 'jelek' termasuk dalam antonim mutlak. Hal itu terbukti dari kata apik jika dinegasikan menjadi ora apik. Frasa ora apik 'tidak bagus' artinya sama dengan elek 'jelek'. Dan sebaliknya, jika kata elek 'jelek' dinegasikan dengan menggunakan kata tidak menjadi ora elek 'tidak jelek, dan frasa ora elek itu artinya sama dengan apik. Contoh penggunaan antonim mutlak tersebut dalam kalimat adalah sebagai berikut.

(2) Omah iku apik. 'Rumah itu bagus'

Kata apik 'bagus' jika dinegasikan dengan kata ora 'tidak', maka kalimat itu menjadi:

(2a) Omah iku ora apik. 'Rumah itu tidak bagus'. 
Frasa ora apik dalam kalimat (2a) sama artinya dengan kata elek 'jelek', sehingga antonim dari kata apik adalah elek.

(2b) Omah iku elek. 'Rumah itu jelek'

Bentuk antonim mutlak ini mengungkapkan kata yang dipertentangkan memiliki batas secara mutlak bukan berupa gradasi (Chaer, 2012). Frasa tanpa ragu memiliki batas yang mutlak dengan frasa keraguan. Hal itu dikarenakan orang yang melakukan sesuatu tanpa ragu maka tidak akan ada keraguan baginya.

\section{c. Keadaan Air}

Air bersifat tidak berwujud, namun wujud air dapat dilihat. Adapun wujud air itu dapat digambarkan dalam antonim mutlak menjadi bening 'jernih' dan butheg 'keruh'.

bening $><$ butheg

Contoh penggunaan antonim mutlak dalam kalimat adalah sebagai berikut.

(3) Banyune butheg. 'Airnya keruh'

(3a) Banyune ora bening. 'Airnya tidak jernih'.

Kata butheg jika dinegasikan menjadi ora butheg. Frasa ora butheg 'tidak keruh' artinya sama dengan bening 'jernih'. Dan sebaliknya, jika kata bening 'jernih' jika dinegasikan dengan menggunakan kata tidak menjadi ora bening 'tidak jernih', dan frasa ora bening itu artinya sama dengan keruh. Berdasarkan hal tersebut maka kata butheg 'keruh' dan murah 'murah' termasuk dalam antonim mutlak. Bentuk antonim mutlak ini mengungkapkan kata yang dipertentangkan memiliki batas secara mutlak bukan berupa gradasi (Chaer, 2012). Frasa tanpa ragu memiliki batas yang mutlak dengan frasa keraguan. Hal itu dikarenakan orang yang melakukan sesuatu tanpa ragu maka tidak akan ada keraguan baginya.

\section{d. Norma}

Norma merupakan nilai-nilai yang berlaku dalam masyarakat, dan nilai itu harus dipegang teguh dan diterapkan dalam kehidupan sehari-hari. Contoh antonim mutlak dalam hal norma dalam Bahasa Jawa adalah sebagai berikut.

$$
\begin{gathered}
\text { pener }><\text { kliru } \\
\text { utama }><\text { nistha }
\end{gathered}
$$

Kata pener 'benar' dan kliru 'salah' termasuk dalam antonim mutlak. Hal itu terbukti dari kata pener jika dinegasikan menjadi ora pener. Frasa ora pener 'tidak benar' artinya sama dengan kliru 'salah'. Dan sebaliknya, jika kata kliru 'salah' dinegasikan dengan menggunakan kata tidak menjadi ora kliru 'tidak salah, dan frasa ora kliru itu artinya sama dengan pener. Contoh penggunaan antonim mutlak tersebut dalam kalimat adalah sebagai berikut. 
(4) Kelakuanmu sing kaya mangkono iku kliru. 'Perbuatanmu yang seperti itu salah'

Kata kliru 'salah' jika dinegasikan dengan kata ora 'tidak', maka kalimat itu menjadi:

(4a) Kelakuanmu sing kaya mangkono iku ora kliru. 'Perbuatanmu yang seperti itu tidak salah'.

Frasa ora kliru dalam kalimat (4a) sama artinya dengan kata pener 'benar', sehingga antonim dari kata kliru adalah pener.

(4b) Kelakuanmu sing kaya mangkono iku pener. 'Perbuatanmu yang seperti itu benar'.

Hubungan kata pada data di atas menunjukkan hubungan koherensi perlawanan. Hubungan ini merupakan bentuk hubungan makna yang mempertentangkan suatu hal dengan hal lainnya (Ramlan, 1993:41).

\section{e. Keadaan Cuaca}

Keadaan cuaca atau suhu di lingkungan sekitar manusia bisa dirasakan. Cuaca yang dimaksud contohnya adalah adhem 'dingin' dan panas 'panas'.

$$
\begin{array}{r}
\text { adhem }><\text { panas } \\
\text { isis }><\text { sumuk }
\end{array}
$$

Contoh penggunaan antonim mutlak dalam kalimat adalah sebagai berikut.

(5) Hawane adhem. 'Cuacanya dingin'

(5a) Hawane ora panas. 'Cuacanya tidak panas'.

Kata adhem jika dinegasikan menjadi ora adhem. Frasa ora adhem 'tidak dingin' artinya sama dengan panas 'panas'. Dan sebaliknya, jika kata panas 'panas' jika dinegasikan dengan menggunakan kata tidak menjadi ora panas 'tidak panas', dan frasa ora panas itu artinya sama dengan adhem 'dingin'. Berdasarkan hal tersebut maka kata adhem 'dingin' dan panas 'panas'termasuk dalam antonim mutlak.

\section{f. Sifat Manusia}

Sifat manusia menunjukkan perilaku yang dilakukan setiap hari. Sifat manusia bermacam-macam, ada yang sesuai norma dan ada yang tidak sesuai norma. Dengan demikian sifat manusia pasti memiliki keterbalikan. Adapun contoh antonim mutlak dalam sifat manusia adalah sebagai berikut.

$$
\begin{gathered}
\text { sregep }><\text { kesed } \\
\text { gemi }><\text { boros } \\
\text { ati-ati }><\text { sembrana }
\end{gathered}
$$


Contoh penggunaan antonim mutlak dalam kalimat adalah sebagai berikut.

(6) Jasmine bocah sregep, nanging Sari bocahe kesed. 'Jasmine anak yang rajin, tetapi Sari anak yang malas'

(6a) Jasmine bocah ora kesed lan Sari bocahe ora sregep. 'Jasmine anak yang tidak malas, dan Sari anak yang tidak rajin.

(7) Salman gemi banget barang dhuwite, beda karo Agus sing boros kae. 'Salman sangat hemat, berbeda dengan Agus yang sangat boros'

(8) Salsa bocahe ati-ati banget, dene Mira bocahe sembrana. 'Salsa anak yang sangat berhati-hati, sedangkan Mira anaknya slengekan'

Kata sregep jika dinegasikan menjadi ora sregep. Frasa ora sregep 'tidak rajin' artinya sama dengan kesed 'malas'. Dan sebaliknya, jika kata kesed 'malas' jika dinegasikan dengan menggunakan kata tidak menjadi ora kesed 'tidak malas', dan frasa ora kesed itu artinya sama dengan sregep 'rajin'. Berdasarkan hal tersebut maka kata sregep 'rajin'dan kesed 'malas' termasuk dalam antonim mutlak.

\section{g. Perasaan Manusia}

Perasaan adalah suatu keadaan yang dirasakan manusia dan bertempat di dalam hati. Perasaan hati manusia dapat disebabkan beberapa alasan. Perasaan itu menyebabkan munculnya berbagai rasa, seperti perasaan senang, atau juga sedih. Gambaran antonim mutlak yang menunjukkan perasaan hati manusia adalah sebagai berikut.

$$
\begin{gathered}
\text { seneng }><\text { sedhih } \\
\text { tresna }><\text { gething } \\
\text { bungah }><\text { susah }
\end{gathered}
$$

Contoh penggunaan antonim mutlak dalam kalimat adalah sebagai berikut.

(9) Aku seneng yen oleh dhuwit. 'Saya senang jika mendapat uang'

(9a) Aku ora sedhih yen oleh dhuwit. 'Saya tidak sedih jika mendapat uang'.

(10) Tasneem tresna marang kowe. 'Tasneem mencintaimu'

(10a) Tasneem ora gething marang kowe. 'Tasneem tidak membencimu'

(11) Simbah bungah atine. 'Nenek senang hatinya'

(11a) Simba hora susah atine. 'Nenek tidak susah hatinya'.

Kata seneng jika dinegasikan menjadi ora seneng. Frasa ora seneng 'tidak gembira artinya sama dengan sedhih 'sedih'. Dan sebaliknya, jika kata sedhih 'sedih' jika dinegasikan dengan menggunakan kata tidak menjadi ora sedhih 'tidak sedih', dan frasa ora sedhih 'tidak sedih' itu artinya sama dengan seneng 'gembira'. Berdasarkan hal tersebut maka kata seneng 'gembira' dan sedhih 'sedih' termasuk dalam antonim mutlak.

Jenis antonim mutlak lainnya yang menunjukkan kata sifat adalah sebagai berikut. 


\section{Tabel 1. Antonim Mutlak berbentuk kata sifat dalam Bahasa Jawa}

\begin{tabular}{clll}
\hline No & Perihal & & Antonim Mutlak \\
\hline 1 & Waktu & saiki 'sekarang' & biyen 'dahulu' \\
2 & Hari pasaran Jawa & Pahing 'hari pertama' & Legi 'hari terakhir' \\
3 & Hari masehi & Sabtu 'hari pertama' & Minggu 'hari terakhir' \\
4 & Bulan & Januari 'bulan pertama' & Desember 'bulan terakhir' \\
5 & Bulan Kalender Jawa & Sura 'bulan pertama' & Besar 'bulan terakhir' \\
6 & Bulan Kalender Islam & Muharram 'bulan pertama' & Dzuhijah 'bulan terakhir' \\
7 & Warna & putih 'warna cerah' & ireng 'warna gelap' \\
8 & Jumlah & akeh 'banyak' & thithik 'sedikit' \\
9 & Keadaan jual & bathi 'untung' & tuna 'rugi' \\
10 & Paras & ayu 'cantik' & elek jelek' \\
& & nggantheng 'ganteng' & elek 'jelek' \\
11 & Rambut & lurus lurus' & kriting 'bergelombang' \\
12 & Hidung & mbangir 'mancung' & pesek 'pesek' \\
13 & Arah & wetan 'timur; & kulon 'barat' \\
& & lor 'utara' & kidul 'selatan' \\
14 & Senjata & landhep 'tajam' & kethul 'tumpul' \\
15 & Jangka waktu & suwe 'lama' & sedhela 'sebentar \\
16 & Tubuh manusia & kuru 'kurus' & lemu 'gemuk' \\
& & dhuwur 'tinggi' & endhik 'pendek' \\
& & cilik 'kecil' & gedhe 'besar' \\
17 & Musim & rendheng 'penghujan' & ketiga 'kemarau' \\
18 & Waktu & esuk 'pagi' & sore 'sore' \\
& & awan 'siang' & wengi 'malam' \\
\hline
\end{tabular}

Semua pasangan antonim mutlak berbentuk kata sifat di atas dapat dinegasikan dengan kata ora 'tidak' seperti pada contoh analisis sebelumnya.

\section{Antonim Mutlak Kata Benda}

Antonim mutlak kata benda merupakan antonim mutlak yang terdiri atas kata benda. Antonim mutlak kata benda berdasarkan perihal benda (Sasangka et al., 2001) yang digambarkan dapat dibedakan menjadi berikut.

\section{a. Tempat}

Tempat menunjukkan suatu benda berada. Yang termasuk antonim mutlak dalam hal tempat adalah sebagai berikut.

$$
\begin{aligned}
\text { nggunung } & ><\text { ngare } \\
\text { njaba } & ><\text { njero } \\
\text { pinggir } & >\text { tengah }
\end{aligned}
$$

Contoh penggunaan antonim mutlak dalam kalimat adalah sebagai berikut.

(12) Omahku manggone ing nggunung. 'Rumahku berada di pegunungan'

(12a) Omahku manggone dudu ing ngare. 'Rumahku berada bukan di pedalaman'.

(13) Kowe neng njaba, aku neng njero. 'Kamu di luar, aku di dalam'

(14) Sawahe ing pinggir dalan. 'Sawahnya di tepi jalan' 
Kata nggunung 'pegunungan' dan ngare 'pedalaman' termasuk dalam antonim mutlak. Hal itu terbukti dari kata nggunung 'pegunungan' jika dinegasikan menggunakan kata dudu 'bukan' menjadi dudu nggunung. Frasa dudu nggunung artinya sama dengan ngare 'pedalaman'. Dan sebaliknya, jika kata ngare 'pedalaman' dinegasikan dengan menggunakan kata $d u d u$ bukan' menjadi dudu ngare 'bukan pedalaman', dan frasa dudu ngare itu artinya sama dengan nggunung. Begitu pula pada kata njaba dan dudu njero, serta pinggir dan dudu tengah semua artinya sama.

\section{b. Isi Dunia}

Segala hal yang ada di dunia ini merupakan ciptaan Tuhan. Isi dunia juga ada yang mengandung antonim mutlak. Yang termasuk antonim mutlak dalam hal isi dunia ini adalah sebagai berikut.

$$
\begin{gathered}
\text { langit }><\text { bumi } \\
\text { segara }><\text { dharatan } \\
\text { swarga }><\text { neraka }
\end{gathered}
$$

Contoh penggunaan antonim mutlak dalam kalimat adalah sebagai berikut.

(15) Bedane kaya langit karo bumi. 'Perbedaannya seperti langit dan bumi'

(16) Sapratelone ndunya iki dharatan, liyane segara. 'sepertiga isi dunia ini adalah darata, sisanya lautan"

Kata langit dan bumi termasuk dalam antonim mutlak. Hal itu terbukti dari kata langit jika dinegasikan menggunakan kata dudu 'bukan' menjadi dudu langit. Frasa $d u d u$ langit artinya sama dengan bumi. Dan sebaliknya, jika kata bumi dinegasikan dengan menggunakan kata $d u d u$ bukan' menjadi dudu bumi, dan frasa dudu bumi itu artinya sama dengan langit.

\section{c. Peralatan Sehari-hari}

Dalam peralatan yang digunakan manusia dalam kehidupan sehari-hari juga mengandung antonim mutlak. Yang termasuk antonim mutlak dalam hal peralatan manusia ini adalah sebagai berikut.

$$
\begin{aligned}
& \text { garpu }><\text { sendhok } \\
& \text { bantal }><\text { guling }
\end{aligned}
$$

Contoh penggunaan antonim mutlak dalam kalimat adalah sebagai berikut.

(17) Aku arep tuku garpu karo sendhok. 'Saya akan membeli garbu dan sendok'

(18) Nalika turu mesthi nggawe bantal karo guling. 'Saat tidur pasti memakai bantal dan guling' 
Kata garpu dan sendhok termasuk dalam antonim mutlak. Hal itu terbukti dari kata garpu jika dinegasikan menggunakan kata $d u d u$ 'bukan' menjadi dudu garpu. Frasa dudu garpu artinya sama dengan sendhok. Dan sebaliknya, jika kata sendhok dinegasikan dengan menggunakan kata $d u d u$ bukan' menjadi $d u d u$ sendhok, dan frasa dudu sendhok itu artinya sama dengan garpu.

\section{Antonim Mutlak Kata Kerja}

Antonim mutlak kata kerja merupakan antonim mutlak yang terdiri atas kata kerja. Antonim mutlak kata kerja berdasarkan perihal pekerjaan (Sasangka et al., 2001) yang digambarkan dapat dibedakan menjadi berikut.

\section{a. Mata}

Antonim mutlak yang menggambarkan hal yang dilakukan mata adalah merem 'terpejam' dan melek 'terbuka'.

$$
\text { merem }><\text { melek }
$$

Contoh penggunaan antonim mutlak dalam kalimat adalah sebagai berikut.

(19) Mripatku ora isa merem blas, kudu melek ae rasane 'Mataku tidak bisa terpejam, ingin terbuka terus'

Kata merem dan melek termasuk dalam antonim mutlak. Hal itu terbukti dari kata merem jika dinegasikan menggunakan kata ora 'tidak' menjadi ora merem. Frasa ora merem artinya sama dengan melek. Dan sebaliknya, jika kata melek dinegasikan dengan menggunakan kata ora 'tidak' menjadi ora melek, dan frasa ora melek itu artinya sama dengan merem.

\section{b. Mulut}

Antonim mutlak yang menggambarkan hal yang dilakukan mulut adalah mangap 'terbuka' dan mingkem 'tertutup'.

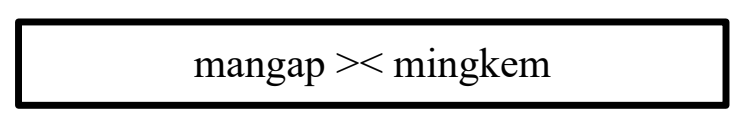

Contoh penggunaan antonim mutlak dalam kalimat adalah sebagai berikut.

(20) Lambene ora bisa mingkem, mangap terus 'Mulutnya tidak bisa diam, bicara terus'

Kata mingkem dan mangap termasuk dalam antonim mutlak. Hal itu terbukti dari kata mingkem jika dinegasikan menggunakan kata ora 'tidak' menjadi ora mingkem. Frasa ora mingkem artinya sama dengan mangap. Dan sebaliknya, jika kata mangap dinegasikan dengan menggunakan kata ora 'tidak' menjadi ora mangap, dan frasa ora mangap itu artinya sama dengan mingkem.

\section{c. Berbicara}

Antonim mutlak dalam hal berbicara ada beberapa contoh sebagai berikut. 


$$
\begin{gathered}
\text { nyacad }><\text { ngelem } \\
\text { mrentah }><\text { menging }
\end{gathered}
$$

Contoh penggunaan antonim mutlak dalam kalimat adalah sebagai berikut.

(21) Wong kok bisane mung nyacad wae, ora tau bisa ngelem. 'Orang kok hanya bisa mencela, tidak pernah memuji'

Kata nyacad dan ngelem termasuk dalam antonim mutlak. Hal itu terbukti dari kata nyacad jika dinegasikan menggunakan kata ora 'tidak' menjadi ora nyacad. Frasa ora nyacad artinya sama dengan ngelem. Dan sebaliknya, jika kata ngelem dinegasikan dengan menggunakan kata ora 'tidak' menjadi ora ngelem, dan frasa ora ngelem itu artinya sama dengan nyacad.

Berdasarkan paparan dan analisis data di atas, jenis-jenis antonim yang ditemukan melengkapi hasil kajian sebelumnya yang dilakukan oleh Sayidirahimova (2020). Dalam antonim mutlak Bahasa Jawa ada antonim khusus pada kata untuk penyebutan nama bulan pada kalender Jawa. Selain itu antonim mutlak antonim mutlak merupakan pasangan kata yang sudah tetap dan pasti, pasangan kata sebagai antonim itu tidak dapat digantikan dengan kata lain, dan jika dinegasikan, maka maknanya sama dengan pasangan antonimnya. Hasil ini sesuai dengan apa yang telah dipaparkan oleh Samenko et al. (2020) yang menyatakan bahwa ada pertautan konflik antara sinonim dan antonim. Adapun rumus antonim mutlak adalah sebagai berikut.

$$
\begin{array}{r}
\mathrm{A}><\mathrm{B} \\
\text { dudu } \mathrm{A}=\mathrm{B} \\
\text { ora } \mathrm{A}=\mathrm{B} \\
\text { dudu } \mathrm{B}=\mathrm{A} \\
\text { ora } \mathrm{B}=\mathrm{A}
\end{array}
$$

Pola tersebut diharapkan dapat mempermudah pemahaman konsep tentang perbedaan sinonim dan antonim serta dapat diteruskan dalam pembelajaran Bahasa oleh guru yang selama ini hanya menerangkan langsung pada contoh antonim. Hal ini terbukti bahwa metode pengajaran dengan metode pola telah efektif untuk membedakan antara hubungan, dalam hal ini hubungan antara antonim dan sinonim (Nguyen et al., 2017) khususnya dalam upaya untuk mempertahankan bahasa daerah termasuk Bahasa Jawa di dalamnya (Prasetya et al., 2020).

\section{PENUTUP}

Berdasarkan uraian di atas dapat disimpulkan bahwa arti kontras bukan berarti kontras yang diketahui dan yang telah diajarkan di sekolah-sekolah selama ini. Selama ini, antonim dimaknai hanya perlawanan kata semata, seperti besar-kecil, hidup-mati, dan sebagainya. Padahal berdasarkan makna yang dijelaskan oleh para ahli, ternyata makna antonim lebih kompleks apalagi jenis antonim juga sangat 
banyak. Pada antonim mutlak, ada beberapa sifat yang harus terpenuhi, A dan B dikatakan sebagai antonim mutlak jika A dinegasikan, maknanya sama dengan $B$, dan sebaliknya jika B dinegasikan maknanya sama dengan A. Pola ini bisa dijadikan rujukan bagi para guru untuk mengajarkan materi makna kontras khususnya pada antonim mutlak.

\section{DAFTAR PUSTAKA}

Abdul, C. (2012). Linguistik Umum. Edisi Revisi. Jakarta: PT Rineka Cipta.

Fauziah, N., Saman, S., \& Syahrani, A. (2017). Relasi Semantik Kata dalam Bahasa Melayu Dialek Mempawah. Jurnal Pendidikan dan Pembelajaran Khatulistiwa, 6(3). https://jurnal.untan.ac.id/index.php/jpdpb/article/view/18908/15875

Guessoum, D., Miraoui, M., \& Tadj, C. (2016). A modification of wu and palmer semantic similarity measure. The Tenth International Conference on Mobile Ubiquitous Computing, Systems, Services and Technologies, 42-46.

Irfanuddin, A. F., \& Halimi, H. (2019). Antonim dalam Al-Quran Surat Ar-Rum Berdasarkan Perspektif Al-Khummas: Kajian Semantik. Semnasbama (Seminar Nasional Bahasa Arab) III. http://prosiding.arabum.com/index.php/semnasbama/article/view/447

Keraf, G. (1993). Komposisi. Ende-Flores: Nusa Indah.

Mashudi, J., Salem, L., \& Syahrani, A. (n.d.). Relasi Makna Adjektiva Dasar Dalam Bahasa Madura Di Kelurahan Kauman Kecamatan Benua Kayong, Ketapang. Jurnal Pendidikan dan Pembelajaran Khatulistiwa, 7(1). https://jurnal.untan.ac.id/index.php/jpdpb/article/download/23727/18622

Miles, M. B., \& Huberman, A. M. (1994). Qualitative Data Analysis: An Expanded Sourcebook. London: SAGE Publications.

Nguyen, K. A., Walde, S. S. im, \& Vu, N. T. (2017). Distinguishing Antonyms and Synonyms in a Pattern-based Neural Network. Proceedings of the 15th Conference of the European Chapter of the Association for Computational Linguistics: Volume 1, Long Papers, 76-85. https://aclanthology.org/E17-1008.pdf

Ningrum, H. A. (2020). Analisis Relasi Makna (التّضاد/AT-TADAT/"Antonim") dalam Surah Al-Mu"Minun dan An-Nūr. https://repositori.usu.ac.id/handle/123456789/26918

Padmosoekotjo, S. (1956). A Ngengrengan Kasusutraan Djawa I. Yogyakarta: Hien Hoo Sing.

Pateda, M. (2010). Semantik Leksikal. Jakarta: PT. Rineka Cipta.

Prasetya, K. H., Subakti, H., \& Septika, H. D. (2020). Pemertahanan Bahasa Dayak Kenyah di Kota Samarinda. Diglosia: Jurnal Kajian Bahasa, Sastra, Dan Pengajarannya, 3(3), 295-304. https://doi.org/10.30872/diglosia.v3i3.77

Ridlo, U. (2017). Sinonim dan Antonim dalam Al-Qur'an. Jurnal Al Bayan: Jurnal Jurusan Pendidikan Bahasa Arab, 9(2), 281-295. https://doi.org/10.24042/albayan.v9i2.2253

Samenko, I., Tikhonov, A., \& Yamshchikov, I. P. (2020). Synonyms and Antonyms: Embedded Conflict. ArXiv, abs/2004.12835. https://export.arxiv.org/pdf/2004.12835

Sasangka, S. S. T. W., Soedibyo, M., \& Ayu, B. R. (2001). Paramasastra Gagrag Anyar Basa Jawa. Jakarta: Yayasan Paramalingua.

Sayidirahimova, N. S. (2020). Semantic Classification of the Syntax Antonyms of 
Uzbek Language. International Scientific Journal Theoretical \& Applied Sciences, 04(84), 670-673.

Setiarini, N. L. P. (2018). Struktur Informasi Antonim Teks Alkitab Bahasa Inggris dan Terjemahannya dalam Bahasa Indonesia. http://niluhputu_s.staff.gunadarma.ac.id/Downloads/files/74294/Hasil+Pe nelitian_Ni+Luh+Putu+Setiarini.pdf

Setiawaty, R., Sabardila, A., Markhamah, M., \& Santoso, T. (2021). Bentuk-Bentuk Sinonimi dan Antonimi dalam Wacana Autobiografi Narapidana: Kajian Aspek Leksikal. Estetika: Jurnal Pendidikan Bahasa dan Sastra Indonesia, 2(2), 79101. https://ejurnal.stkippgrisumenep.ac.id/index.php/ESTETIKA/article/view/145

Sudaryanto. (1993). Metode dan Aneka Teknik Analisis Bahasa: Pengantar Penelitian Wahana Kebudayaan Secara Linguistis. Yogyakarta: Duta Wacana University Press.

Sugita, A., \& Mus, A. H. (2019). Bentuk Antonim Bahasa Modo pada Masyarakat Pulau Komodo. Jurnal Ilmiah Telaah, 4(2), 36-40. https://journal.ummat.ac.id/index.php/telaah/article/view/1224

Suhartatik, S., \& Azis, A. (2019). Studi Relasi Makna Nomina Bahasa Madura di Kabupaten Sumenep (Kajian Semantik Hiponimi). Konferensi Nasional Bahasa $\begin{array}{llll}\text { Dan Sastra } & V, & 5(1), & 268-273 .\end{array}$ https://jurnal.fkip.uns.ac.id/index.php/knbs/article/view/12905

Tumanggor, I. (2020). Antonim dalam Al-Quran Surat Al-Lail. WARAQAT: Jurnal Ilmu-Ilmu Keislaman, 4(2), 14. https://doi.org/10.51590/waraqat.v4i2.82 
